\title{
An Empirical Study of the Improvement of the Product Supply Chains in terms of Reducing Environmental Pollution in China
}

\author{
Ci Jiaojin \\ Institute of Economy and Management, Nanyang Normal University, Nanyang, \\ Henan, China \\ jiaojin2008321@163.com
}

\begin{abstract}
There is an increasing recognition that the organizations must address the issues of environmental protection with the development of the economy and society, and it is becoming a matter of obligation rather than choice to adopt more environmentally friendly behavior. It is known to all that China is one of the global manufacturing countries. However the Chinese government has realized the responsibility of reducing the pollution and the protection of the environment is one of the basic state policies. This paper is an attempt to testify the improvement of reducing environment pollution and identify the current issues in environmental pollution of the companies from the supply chain perspective in China. Grey approach is employed to evaluate the improvement of the product supply chains in terms of reducing environmental pollution in China. The managerial implications and suggestions for future research are discussed in this paper.
\end{abstract}

Keywords: Environment pollution, Supply chain, Grey approach, Empirical study

\section{Introduction}

With the increasing ecological problems of environment pollution and energy shortage around the world, the business activities which have impact on the environment have been closely scrutinized by the governments in recent years [1-5]. For the first ten years of the $21^{\text {st }}$ century, China had achieved rapid development, with high rates of urbanization and industrialization. As a result, it faces some resource related and environmental challenges in terms of dealing with the balance of the industrialization and environment protection. China is the largest developing country in the world, and China's energy consumption has exceeded that of the United States, which means that China is the largest energy consumer country and greenhouse gas emitter in the world due to the huge population and China's economy as one of the global manufacturing countries and the primary trading partner for many nations.

Not surprisingly, Chinese government has realized the responsibility to reduce the greenhouse gas emission and protect the environment. For example, the Chinese government has listed climate change, energy saving and carbon reduction as the main policies in the national $11^{\text {th }}$ Five-year plan (2005-2010). Since the manufacturing industry has the problem of high emission of pollution, it is definitely the main target for the greenhouse gas reduction measures. The related environmental policies increase the pressure on companies to adopt environmentally responsible business practices and green their supply chains [6]. The companies not only focus on the greenhouse gas and other pollutant emission reduction in their own companies, but also dictating the same 
requirements to the supply chain companies such as their manufactures and retailers [7$11]$.

This paper is an attempt to identify the current issues in environmental pollution of the companies in China from the supply chain perspective and testify the effect of the related polices regarding to saving energy and reducing carbon emission implemented since 2005. The paper is organized as follows. The next section introduces the related literature about green supply chain. Following is a brief introduction about the Grey approach used in this research. Section 4 describes the data analysis of identify the improvement of product supply chain in terms of reducing the environment pollution in China. The primary data for this research are collected from Office for National Statistics in China. Finally, major issues and challenges for the local governments to instruct the companies in terms of promoting their products with lower pollution emission are identified and discussed along with the related managerial implications.

\section{Literature Review}

When talking about green initiatives, one shall think on a supply chain basis instead of on a company basis, since the competition no longer takes place between companies, but between supply chains [12]. In order to retain and increase supply chains, competitiveness, the initiatives, be they "green thinking" or "lean", must be adopted by the whole supply chain and coordinated by the focal company [13-17]. There is not a widely accepted concept for green supply chain and green supply chain management. Srivastava [18] defines green supply chain management as integrating environmental thinking into supply chain management, including product design, material sourcing and selection, manufacturing processes, delivery of the final product to the consumers, as well as end-of-life management of the product after its useful life. Bowen, et al., [19] argue that green supply chain management refers to a buying company's plans and activities that integrated environmental issues into supply chain management in order to improve the environmental performance.

Being green becomes an advantage for the companies and in turn, their supply chains. Environmentally conscious consumers use their influence through their choice of company, increasing green companies' and supply chains' competitiveness and economic performance [20, 21]. Pretty, et al., [22] produced a preliminary evaluation of externalities from UK agriculture reflecting the importance of water pollution, biodiversity loss and soil erosion. Sarkis [23] proposes a strategy decision framework for green supply chain management based on the related literature and practice in the area of environmentally conscious business practices. Aballahe, et al., [24] suggest that companies intended to green their supply chains should focus on improving the efficiency of the manufacturing, handling, and routing of goods through technical, operational, and logistical measures. The research of Larsen, et al., [25] indicates that for most sectors a majority of the energy or environmental loads are located in the upstream supply chain, both nationally and abroad. Andic, et al., [26] propose a conceptual model regarding dynamics of interdependency and interaction within the upstream and downstream partners in the chain in terms of green consciousness. Rostamzadeh, et al., [27] illustrate the case of a laptop manufacturer in Malaysia that pursues to evaluate green supply chain management (GSCM) indicators among its practitioners. The results indicat that the main criteria of their research ranked as follows respectively: eco-design, green production, green purchasing, green recycling, green transportation and green warehousing.

In summary, the environmental performance for the manufacturing industry has proven to be very important. However, there have been limited researches in the current literature focusing on the major issues and challenges for the local governments to instruct the companies in terms of promoting their products with lower pollution emission in China - 
the largest manufacturing country in the world, which is the primary promotion of this study.

\section{Methodology}

\subsection{Grey System Theory}

Grey system theory which can help evaluate outcomes under the situation with incomplete and indeterminate information is first proposed in 1982 [28]. Considering the incomplete information in this paper, grey approach which has been recognized as an effective tool to solve this kind of the problems is adopted to select the leading industries.

To introduce some fundamental aspects of grey system theory, some basic definitions and notation are shown as follows:

$x$ is denoted as a closed and bounded set of real numbers. A grey number, $\otimes x$, is defined as an interval with known upper and lower bounds but unknown distribution information for $x$ (Deng, 1989), which is,

$$
\otimes x=[\underline{\otimes} x, \bar{\otimes} x]=\left[x^{\prime} \in x \mid \underline{\otimes} x \leq x^{\prime} \leq \bar{\otimes} x\right]
$$

where $\underline{\otimes}$ and $\bar{\otimes} x$ are the lower and upper bounds of $\otimes x$ respectively.

Expressions belowing demonstrate some basic grey number mathematical operations:

$$
\begin{aligned}
& \otimes x_{1}+\otimes x_{2}=\left[\underline{x_{1}}+\underline{x_{2}}, \overline{x_{1}}+\overline{x_{2}}\right] \\
& \otimes x_{1}-\otimes x_{2}=\left[\underline{x_{1}}-\overline{x_{2}}, \overline{x_{1}}-\underline{x_{2}}\right] \\
& \otimes x_{1} \times \otimes x_{2}=\left[\min \left(\underline{x_{1}} \underline{x_{2}}, \underline{x_{1}} \overline{x_{2}}, \overline{x_{1}} \underline{x_{2}}, \overline{x_{1}} \overline{x_{2}}\right), \max \left(\underline{x_{1}} \underline{x_{2}}, \underline{x_{1}} \overline{x_{2}}, \overline{x_{1}} \underline{x_{2}}, \overline{x_{1}} \overline{x_{2}}\right)\right] \\
& \otimes x_{1} \div \otimes x_{2}=\left[\underline{x_{1}}, \overline{x_{1}}\right] \times\left[\frac{1}{\underline{x_{2}}}, \underline{\frac{1}{x_{2}}}\right]
\end{aligned}
$$

\subsection{The Grey Approach}

Below is a briefly review of relevant definitions and the calculation procedure for the GRA approach.

GRA uses several small sub-problems to present the decision problem, and the problem is decomposed into a hierarchy with a goal at the top, criteria and sub-criteria at levels and sub-levels and decision alternatives at the bottom of the hierarchy.

The comparison matrix involves the comparison in pairs of the elements of constructed hierarchy. The aim is to set their relative priorities with respect to each of the elements at the next higher level.

$$
\begin{aligned}
& \begin{array}{lllll}
C_{1} & C_{2} & C_{3} & \cdots & C_{n}
\end{array}
\end{aligned}
$$

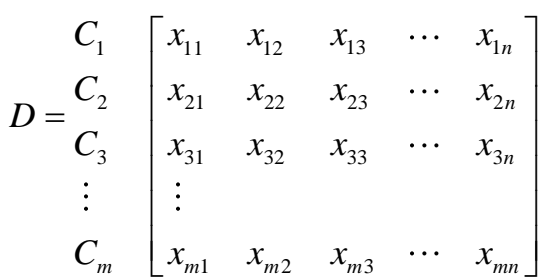

Where $x_{i j}$ is the degree preference of $i^{\text {th }}$ year over $j^{\text {th }}$ criterion. Before the calculation of vector of priorities, the comparison matrix has to be normalized into the range of $[0,1]$ by the equation below:

The larger, the better type [29]: 


$$
y_{i j}=\frac{\left[x_{i j}-\min \left\{x_{i j}\right\}\right]}{\left[\max \left\{x_{i j}\right\}-\min \left\{x_{i j}\right\}\right]}
$$

The smaller, the better type:

$$
y_{i j}=\frac{\left[\max \left\{x_{i j}\right\}-x_{i j}\right]}{\left[\max \left\{x_{i j}\right\}-\min \left\{x_{i j}\right\}\right]}
$$

The normalized decision matrix is denoted by $Y=\left[y_{i j}\right]_{m \times n}$.

Let $\otimes w=\left\{\otimes w_{1}, \otimes w_{2}, \cdots \otimes w_{n}\right\}$ is the vector of criteria weights. Linguistic variables are adopted in this research, as shown in Table 1:

Table 1. Scale of Attribute Weights

\begin{tabular}{lcc}
\hline Rank & Sub-criteria grade & Membership function \\
\hline Very Low (VL) & 1 & {$[0.00,0.10]$} \\
Low (L) & 2 & {$[0.10,0.30]$} \\
Medium Low (ML) & 3 & {$[0.30,0.40]$} \\
Medium (M) & 4 & {$[0.40,0.50]$} \\
Medium High (MH) & 5 & {$[0.50,0.60]$} \\
High (H) & 6 & {$[0.60,0.90]$} \\
Very High (VH) & 7 & {$[0.90,1.00]$} \\
\hline
\end{tabular}

The criteria rating value is shown in Table 2 :

Table 2. Scale of Attribute Weights

\begin{tabular}{lcc}
\hline Rank & Sub-criteria grade & Membership function \\
\hline Very Poor (VP) & 1 & {$[0.00,1.00]$} \\
Poor (P) & 2 & {$[0.10,0.30]$} \\
Medium Low (ML) & 3 & {$[0.30,0.40]$} \\
Medium (M) & 4 & {$[0.40,0.50]$} \\
Medium High (MH) & 5 & {$[0.50,0.60]$} \\
High (H) & 6 & {$[0.60,0.90]$} \\
Very High (VH) & 7 & {$[0.90,1.00]$} \\
\hline
\end{tabular}

The detailed procedure is summarized as follows:

Step 1: Criteria weight identification

If the decision maker group has $\mathrm{K}$ raters, then the criteria weight is calculated using:

$$
\otimes w_{j}=\frac{1}{K}\left[\otimes w_{j}^{1}+\otimes w_{j}^{2}+\cdots \otimes w_{j}^{K}\right]
$$

Where $\otimes w_{j}^{K}(j=1,2, \cdots, n)$ is the criteria weight of $K^{\text {th }}$ rater and can be described by Grey number $\otimes w_{j}^{K}=\left[\underline{w}_{j}^{K}, \bar{w}_{j}^{K}\right]$.

Step 2: Criteria rating value in linguistic variables

Criteria rating value in linguistic variables are calculated using

$$
\otimes Y_{i j}=\frac{1}{K}\left[\otimes Y_{i j}^{1}+\otimes Y_{i j}^{2}+\cdots \otimes Y_{i j}^{K}\right]
$$

Where $\otimes Y_{i j}^{K}(i=1,2, \cdots, m ; j=1,2, \cdots, n)$ is the criteria weight of $K^{\text {th }}$ rater and can be described by Grey number $\otimes Y_{i j}^{K}=\left[\underline{Y}_{i j}^{K}, \bar{Y}_{i j}^{K}\right]$.

Step 3: Establish the normalized grey decision matrix: 
Since we had already normalized the decision matrix in the GRA process, then we should transfer the normalized numbers in the decision matrix into Grey numbers.

$$
D=\left[\begin{array}{lllll}
\otimes Y_{11} & \otimes Y_{12} & \otimes Y_{13} & \cdots & \otimes Y_{1 n} \\
\otimes Y_{21} & \otimes Y_{22} & \otimes Y_{23} & \cdots & \otimes Y_{2 n} \\
\otimes Y_{31} & \otimes Y_{32} & \otimes Y_{33} & \cdots & \otimes Y_{3 n} \\
\vdots & & & & \\
\otimes Y_{m 1} & \otimes Y_{m 2} & \otimes Y_{m 3} & \cdots & \otimes Y_{m n}
\end{array}\right]
$$

Step 4: Establish the weighted normalized Grey decision matrix

The weighted normalized Grey decision matrix can be derived by the normalized Grey decision matrix and criteria weights by the equation as follows:

$\otimes V_{i j}=\otimes Y_{\mathrm{ij}} \times \otimes W_{j}$

Then the weighted normalized Grey decision matrix can be established as follows:

$D=\left[\begin{array}{lllll}\otimes V_{11} & \otimes V_{12} & \otimes V_{13} & \cdots & \otimes V_{1 n} \\ \otimes V_{21} & \otimes V_{22} & \otimes V_{23} & \cdots & \otimes V_{2 n} \\ \otimes V_{31} & \otimes V_{32} & \otimes V_{33} & \cdots & \otimes V_{3 n} \\ \vdots & & & & \\ \otimes V_{m 1} & \otimes V_{m 2} & \otimes V_{m 3} & \cdots & \otimes V_{m n}\end{array}\right] \begin{array}{r}\text { Step 5: Set ideal solution for the } \\ \text { alternatives }\end{array}$ $S^{\max }=\left\{\left[\max _{1 \leq i \leq m} \underline{V}_{i 1}, \max _{1 \leq i \leq m} \bar{V}_{i 1}\right],\left[\max _{1 \leq i \leq m} \underline{V}_{i 2}, \max _{1 \leq i \leq m} \bar{V}_{i 2}\right], \cdots,\left[\max _{1 \leq i \leq m} V_{i n}, \max _{1 \leq i \leq m} \bar{V}_{i n}\right]\right\}$

Step 6: Calculate the Grey possibility

Compare the alternatives set $A=\left\{A_{1}, A_{2}, \cdots A_{m}\right\}$ with the ideal solution $A^{\text {max }}$ :

$$
P\left\{A_{i} \leq A^{\max }\right\}=\frac{1}{n} \sum_{j=1}^{n}\left\{\otimes V_{i j} \leq \otimes Y_{j}^{\max }\right\}
$$

Step 7: Prioritize the industries

Sort the alternative industries based on $P\left\{A_{i} \leq A^{\max }\right\}$ comparison. If $A_{i}$ value is smaller, the ranking order of $A_{i}$ is better. Otherwise, the ranking order is worse.

\section{Data Collection and Results Analysis}

This research is focused on the major issues and challenges for the local governments to instruct the companies in terms of promoting their product supply chains with lower pollution emission, and the specific measures are listed and named in Table 3, which including comprehensive situation, pollutant emission, pollution management and transport energy. The decision problem consists of three levels: at the highest level, the objective of the problem is situated while in the second level, the three aspects are listed, and in the third level, the criteria are listed. The related data from 2003 to 2015 year is collected from the Office for National Statistics in China.

\section{Table 3. The measures of Evaluating Pollution Emission from Supply Chain Perspective}

\begin{tabular}{|l|l|l|}
\hline Goal & Aspects & Criteria \\
\hline & C1 Pollutant & $S C_{1}$ Nox emissions per unit of output \\
& Emission & $\mathrm{SC}_{2}$ chemical oxygen demand per unit of output \\
& $\mathrm{SC}_{3}$ Wastewater emission per unit of output \\
& $\mathrm{SC}_{4}$ Sulfur dioxide emissions per unit of output \\
\hline
\end{tabular}




\begin{tabular}{|c|c|c|}
\hline \multirow{3}{*}{$\begin{array}{l}\text { The } \\
\text { measures of } \\
\text { evaluating } \\
\text { pollution } \\
\text { emission in } \\
\text { product } \\
\text { industry } \\
\text { from supply } \\
\text { chain } \\
\text { perspective }\end{array}$} & $\begin{array}{l}C 2 \\
\text { Comprehensive } \\
\text { Situation }\end{array}$ & $\begin{array}{l}S C_{5} \text { Energy production per unit of output } \\
S C_{6} \text { Electric power consumption per unit of output } \\
S C_{7} \text { Energy consumption per unit of output } \\
S C_{8} \text { Industrial water consumption per unit of output }\end{array}$ \\
\hline & $\begin{array}{l}\text { C3 Pollutant } \\
\text { Management }\end{array}$ & $\begin{array}{l}S C_{9} \text { Industrial pollution control investment per unit of } \\
\text { output } \\
S C_{10} \text { Waste water management investment per unit of output } \\
S C_{11} \text { Waste gas project management investment per unit of } \\
\text { output } \\
S C_{12} \text { Solid waste management investment per unit of output }\end{array}$ \\
\hline & $\begin{array}{l}\text { C4 Transport } \\
\text { Energy }\end{array}$ & $\begin{array}{l}S C_{13} \text { Freight volume per unit of output } \\
S C_{14} \text { Freight turnover per unit of output } \\
S C_{15} \text { Railway freight volume per unit of output }\end{array}$ \\
\hline
\end{tabular}

The important degrees of the above sub-criteria weights are given with linguistic terms, i.e., $\mathrm{VL}, \mathrm{L}, \mathrm{M}, \mathrm{H}$, and $\mathrm{VH}$, employed by five experts $E_{1}, E_{2}, E_{3}, E_{4}$, and $E_{5}$, as shown in Table 3.

Table 3. The Linguistic Weights Given by Five Experts

\begin{tabular}{|c|c|c|c|c|c|c|}
\hline Criteria & Sub- Criteria & $\boldsymbol{E}_{\boldsymbol{1}}$ & $\boldsymbol{E}_{\boldsymbol{2}}$ & $\boldsymbol{E}_{\mathbf{3}}$ & $\boldsymbol{E}_{\boldsymbol{4}}$ & $\boldsymbol{E}_{\boldsymbol{5}}$ \\
\hline \multirow{4}{*}{$\begin{array}{c}\text { Pollutant } \\
\text { Emission }\end{array}$} & $S C_{1}$ & $\mathrm{M}$ & $\mathrm{ML}$ & $\mathrm{ML}$ & $\mathrm{ML}$ & $\mathrm{ML}$ \\
\cline { 2 - 7 } & $S C_{2}$ & $\mathrm{M}$ & $\mathrm{M}$ & $\mathrm{M}$ & $\mathrm{MH}$ & $\mathrm{MH}$ \\
\cline { 2 - 7 } & $S C_{3}$ & $\mathrm{VH}$ & $\mathrm{VH}$ & $\mathrm{H}$ & $\mathrm{H}$ & $\mathrm{MH}$ \\
\hline \multirow{4}{*}{$\begin{array}{c}\text { Comprehensi } \\
\text { ve Situation }\end{array}$} & $S C_{4}$ & $\mathrm{M}$ & $\mathrm{ML}$ & $\mathrm{M}$ & $\mathrm{MH}$ & $\mathrm{M}$ \\
\cline { 2 - 7 } & $S C_{5}$ & $\mathrm{VH}$ & $\mathrm{H}$ & $\mathrm{VH}$ & $\mathrm{VH}$ & $\mathrm{VH}$ \\
\cline { 2 - 7 } & $S C_{6}$ & $\mathrm{VH}$ & $\mathrm{VH}$ & $\mathrm{MH}$ & $\mathrm{MH}$ & $\mathrm{H}$ \\
\hline \multirow{4}{*}{\begin{tabular}{c} 
Pollutant \\
\cline { 2 - 7 }
\end{tabular}} & $S C_{7}$ & $\mathrm{VH}$ & $\mathrm{VH}$ & $\mathrm{VH}$ & $\mathrm{VH}$ & $\mathrm{VH}$ \\
\cline { 2 - 7 } & $S C_{8}$ & $\mathrm{VH}$ & $\mathrm{H}$ & $\mathrm{VH}$ & $\mathrm{H}$ & $\mathrm{VH}$ \\
\cline { 2 - 7 } & $S C_{9}$ & $\mathrm{VH}$ & $\mathrm{H}$ & $\mathrm{MH}$ & $\mathrm{H}$ & $\mathrm{MH}$ \\
\cline { 2 - 7 } & $S C_{10}$ & $\mathrm{VH}$ & $\mathrm{H}$ & $\mathrm{VH}$ & $\mathrm{VH}$ & $\mathrm{VH}$ \\
\hline \multirow{3}{*}{$\begin{array}{c}\text { Transport } \\
\text { Energy }\end{array}$} & $S C_{11}$ & $\mathrm{H}$ & $\mathrm{MH}$ & $\mathrm{VH}$ & $\mathrm{VH}$ & $\mathrm{H}$ \\
\cline { 2 - 7 } & $S C_{12}$ & $\mathrm{MH}$ & $\mathrm{H}$ & $\mathrm{H}$ & $\mathrm{VH}$ & $\mathrm{H}$ \\
\cline { 2 - 7 } & $S C_{13}$ & $\mathrm{M}$ & $\mathrm{ML}$ & $\mathrm{M}$ & $\mathrm{M}$ & $\mathrm{ML}$ \\
\hline
\end{tabular}

In the next step, we calculate the average of the elements of each row, then the average criteria weights are derived as follows: $W_{1}=[0.32,0.42], W_{2}=[0.44,0.54], W_{3}=[0.70,0.88]$, $W_{4}=[0.40,0.50], \quad W_{5}=[0.84,0.98], \quad W_{6}=[0.68,0.82], \quad W_{7}=[0.90,1.00], \quad W_{8}=[078,0.96]$, $W_{9}=[0.62,0.80], W_{10}=[0.84,0.98], W_{11}=[0.70,0.88], W_{12}=[0.64,0.86], W_{13}=[0.36,0.46]$, $W_{14}=[0.44,0.54], W_{15}=[0.26,0.36]$.

Considering the limitation of this page, only part of the normalized decision matrix is shown in Table 4.

Table 4. The Normalized Decision Matrix

\begin{tabular}{cccccccccccc}
\hline Year. & $S C_{1}$ & $S C_{2}$ & $S C_{3}$ & $S C_{4}$ & $S C_{5}$ & $S C_{6}$ & $S C_{7}$ & $S C_{8}$ & $S C_{9}$ & $S C_{10}$ & $S C_{11}$ \\
\hline 2013 & 0.56 & 0.44 & 0.31 & 1.00 & 0.88 & 0.77 & 0.61 & 0.33 & 0.02 & 0.00 & 0.56 \\
2012 & 0.63 & 0.51 & 0.38 & 1.00 & 0.87 & 0.75 & 0.58 & 0.33 & 0.12 & 0.00 & 0.63 \\
2011 & 1.00 & 0.94 & 0.91 & 0.85 & 0.74 & 0.65 & 0.53 & 0.39 & 0.09 & 0.00 & 1.00 \\
2010 & 1.00 & 0.95 & 0.88 & 0.82 & 0.71 & 0.60 & 0.43 & 0.18 & 0.01 & 0.00 & 1.00 \\
2009 & 1.00 & 0.93 & 0.88 & 0.80 & 0.69 & 0.62 & 0.49 & 0.27 & 0.09 & 0.00 & 1.00 \\
2008 & 1.00 & 0.13 & 0.11 & 0.12 & 0.11 & 0.09 & 0.03 & 0.01 & 0.00 & 0.00 & 1.00 \\
2007 & 1.00 & 0.95 & 0.89 & 0.81 & 0.65 & 0.57 & 0.40 & 0.21 & 0.08 & 0.00 & 1.00
\end{tabular}




\begin{tabular}{llllllllllll}
2006 & 1.00 & 0.94 & 0.86 & 0.77 & 0.68 & 0.58 & 0.44 & 0.28 & 0.14 & 0.00 & 1.00 \\
2005 & 0.61 & 0.05 & 0.00 & 0.00 & 0.23 & 0.60 & 0.80 & 0.85 & 1.00 & 0.56 & 0.61 \\
2004 & 0.00 & 0.11 & 0.25 & 0.18 & 0.42 & 0.83 & 1.00 & 0.85 & 0.88 & 0.73 & 0.00 \\
\hline
\end{tabular}

In the next step, the Grey variables discussed in Section 3.3 is applied to transform Table 4 into Table 5vas explained by the following example. If the numeric rating is 0.01 , then its Grey variable is "VL". Therefore, the new pairwise comparison matrix is shown in Table 5:

Table 5. Part of the Normalized Decision Matrix using Grey Variables

\begin{tabular}{cccccccccccc}
\hline Year & $S C_{1}$ & $S C_{2}$ & $S C_{3}$ & $S C_{4}$ & $S C_{5}$ & $S C_{6}$ & $S C_{7}$ & $S C_{8}$ & $S C_{9}$ & $S C_{10}$ & $S C_{11}$ \\
\hline 2013 & $\mathrm{M}$ & $\mathrm{MH}$ & $\mathrm{VH}$ & $\mathrm{VH}$ & $\mathrm{VH}$ & $\mathrm{VH}$ & $\mathrm{VH}$ & $\mathrm{VH}$ & $\mathrm{MH}$ & $\mathrm{VL}$ & $\mathrm{VH}$ \\
2012 & $\mathrm{M}$ & $\mathrm{M}$ & $\mathrm{VH}$ & $\mathrm{VH}$ & $\mathrm{VH}$ & $\mathrm{VL}$ & $\mathrm{VH}$ & $\mathrm{VH}$ & $\mathrm{VL}$ & $\mathrm{VL}$ & $\mathrm{VL}$ \\
2011 & $\mathrm{ML}$ & $\mathrm{ML}$ & $\mathrm{VH}$ & $\mathrm{VH}$ & $\mathrm{VH}$ & $\mathrm{VL}$ & $\mathrm{VH}$ & $\mathrm{VH}$ & $\mathrm{VL}$ & $\mathrm{L}$ & $\mathrm{VL}$ \\
2010 & $\mathrm{VH}$ & $\mathrm{VH}$ & $\mathrm{H}$ & $\mathrm{H}$ & $\mathrm{H}$ & $\mathrm{VL}$ & $\mathrm{H}$ & $\mathrm{H}$ & $\mathrm{VL}$ & $\mathrm{L}$ & $\mathrm{VL}$ \\
2009 & $\mathrm{VH}$ & $\mathrm{VH}$ & $\mathrm{H}$ & $\mathrm{MH}$ & $\mathrm{MH}$ & $\mathrm{VL}$ & $\mathrm{MH}$ & $\mathrm{MH}$ & $\mathrm{L}$ & $\mathrm{ML}$ & $\mathrm{L}$ \\
2008 & $\mathrm{H}$ & $\mathrm{H}$ & $\mathrm{MH}$ & $\mathrm{MH}$ & $\mathrm{MH}$ & $\mathrm{VL}$ & $\mathrm{M}$ & $\mathrm{MH}$ & $\mathrm{MH}$ & $\mathrm{H}$ & $\mathrm{M}$ \\
2007 & $\mathrm{MH}$ & $\mathrm{MH}$ & $\mathrm{M}$ & $\mathrm{M}$ & $\mathrm{M}$ & $\mathrm{VL}$ & $\mathrm{ML}$ & $\mathrm{M}$ & $\mathrm{H}$ & $\mathrm{VH}$ & $\mathrm{MH}$ \\
2006 & $\mathrm{ML}$ & $\mathrm{ML}$ & $\mathrm{ML}$ & $\mathrm{L}$ & $\mathrm{L}$ & $\mathrm{VL}$ & $\mathrm{L}$ & $\mathrm{L}$ & $\mathrm{H}$ & $\mathrm{H}$ & $\mathrm{MH}$ \\
2005 & $\mathrm{VL}$ & $\mathrm{VL}$ & $\mathrm{VL}$ & $\mathrm{VL}$ & $\mathrm{VL}$ & $\mathrm{VL}$ & $\mathrm{VL}$ & $\mathrm{VL}$ & $\mathrm{VH}$ & $\mathrm{VH}$ & $\mathrm{MH}$ \\
2004 & $\mathrm{VL}$ & $\mathrm{VL}$ & $\mathrm{VL}$ & $\mathrm{VL}$ & $\mathrm{VL}$ & $\mathrm{VL}$ & $\mathrm{VL}$ & $\mathrm{VL}$ & $\mathrm{M}$ & $\mathrm{H}$ & $\mathrm{ML}$ \\
\hline
\end{tabular}

The Grey variables of the above matrix are then transformed into a Grey decision marix, as shown in Table 6:

Table 6. Part of the Grey Decision Matrix

\begin{tabular}{cccccccc}
\hline Year & $S C_{1}$ & $S C_{2}$ & $S C_{3}$ & $S C_{4}$ & $S C_{5}$ & $S C_{6}$ & $S C_{7}$ \\
\hline 2013 & {$[0.40,0.50]$} & {$[0.50,0.60]$} & {$[0.90,1.00]$} & {$[0.90,1.00]$} & {$[0.90,1.00]$} & {$[0.90,1.00]$} & {$[0.90,1.00]$} \\
2012 & {$[0.40,0.50]$} & {$[0.40,0.50]$} & {$[0.90,1.00]$} & {$[0.90,1.00]$} & {$[0.90,1.00]$} & {$[0.00,0.10]$} & {$[0.90,1.00]$} \\
2011 & {$[0.30,0.40]$} & {$[0.30,0.40]$} & {$[0.90,1.00]$} & {$[0.90,1.00]$} & {$[0.90,1.00]$} & {$[0.00,0.10]$} & {$[0.90,1.00]$} \\
2010 & {$[0.90,1.00]$} & {$[0.90,1.00]$} & {$[0.60,0.90]$} & {$[0.60,0.90]$} & {$[0.60,0.90]$} & {$[0.00,0.10]$} & {$[0.60,0.90]$} \\
2009 & {$[0.90,1.00]$} & {$[0.90,1.00]$} & {$[0.60,0.90]$} & {$[0.50,0.60]$} & {$[0.50,0.60]$} & {$[0.00,0.10]$} & {$[0.50,0.60]$} \\
2008 & {$[0.60,0.90]$} & {$[0.60,0.90]$} & {$[0.50,0.60]$} & {$[0.50,0.60]$} & {$[0.50,0.60]$} & {$[0.00,0.10]$} & {$[0.40,0.50]$} \\
2007 & {$[0.50,0.60]$} & {$[0.50,0.60]$} & {$[0.40,0.50]$} & {$[0.40,0.50]$} & {$[0.40,0.50]$} & {$[0.00,0.10]$} & {$[0.30,0.40]$} \\
2006 & {$[0.30,0.40]$} & {$[0.30,0.40]$} & {$[0.30,0.40]$} & {$[0.10,0.30]$} & {$[0.10,0.30]$} & {$[0.00,0.10]$} & {$[0.10,0.30]$} \\
2005 & {$[0.00,0.10]$} & {$[0.00,0.10]$} & {$[0.00,0.10]$} & {$[0.00,0.10]$} & {$[0.00,0.10]$} & {$[0.00,0.10]$} & {$[0.00,0.10]$} \\
2004 & {$[0.00,0.10]$} & {$[0.00,0.10]$} & {$[0.00,0.10]$} & {$[0.00,0.10]$} & {$[0.00,0.10]$} & {$[0.00,0.10]$} & {$[0.00,0.10]$} \\
$\otimes W_{j}$ & {$[0.32,0.42]$} & {$[0.44,0.54]$} & {$[0.70,0.88]$} & {$[0.40,0.50]$} & {$[0.84,0.98]$} & {$[0.68,0.82]$} & {$[0.90,1.00]$} \\
\hline
\end{tabular}

Following the resulting Grey weighted decision matrix can be derived based on Table 6 and the weights identified before, and the values of ideal leading industry $A^{\max }$ are shown below for our illustration.

$$
\begin{aligned}
A^{\max }= & \{[0.29,0.42],[0.40,0.54],[0.63,0.88],[0.36,0.50],[0.76,0.98],[0.61,0.82],[0.81,1.00], \\
& {[0.70,0.96],[0.56,0.80],[0.76,0.98],[0.63,0.88],[0.58,0.86],[0.32,0.46],[0.40,0.54], } \\
& {[0.23,0.36]\} }
\end{aligned}
$$

Then the Grey possibility value for each year is given below in Figure 1: 


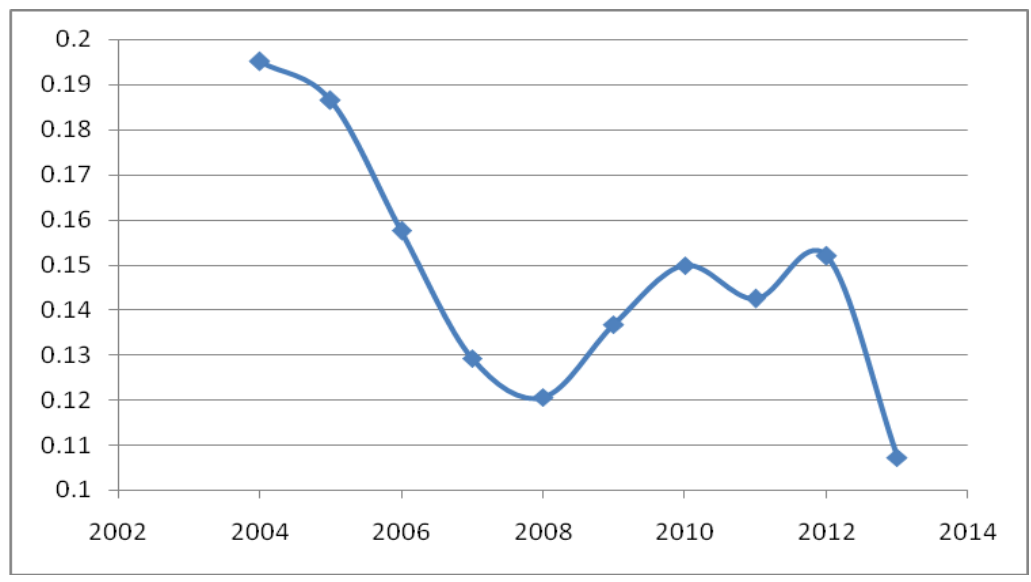

Figure 1. Grey Possibility Value for Each Year

\section{Conclusions and Suggestions for Future Research}

This research is focused on investigating and evaluating the performance of the product supply chains in terms of reduction of pollution emission in recent ten years in China. The objectives for this research are threefold: (1) to examine and evaluate the effectiveness of reduction pollution emission from the supply chain perspective in China; (2) to identify major issues and challenges for those companies in terms of reducing pollution emission in the product supply chain; and (3) to discuss and explore the potential managerial implications for future research.

The primary data for this research are collected from the Office for National Statistics in China. Grey approach is employed to evaluate the effectiveness and the improvement of green supply chains in product industry in China. According to the criteria weights derived from this section earlier, the relative top four important measures to evaluate the performance of green supply chain are (1) $\mathrm{SC}_{7}$ : Energy consumption per unit of output, and its weight $=[0.90,1.00]$; (2) $\mathrm{SC}_{5}$ : Energy production per unit of output, and its weight $=[0.84,0.98]$; (3) $\mathrm{SC}_{10}$ Waste water management investment per unit of output, and its weight $=[0.84,0.98]$; and (4) $\mathrm{SC}_{8}$ Industrial water consumption per unit of output, and its weight $=[0.78,0.96]$. As such, the companies should pay more attention to these measures and take effective measures to performance better in these criteria.

Based on the results of this research, there is obvious improvement for the products companies in terms of the reducing the pollution emission in order to green their supply chains since 2004 in China. However, the performance of reducing environmental pollution of the companies from the supply chain perspective from 2009-2012 went down to an unsatisfactory level which implying that the awareness of environmental protection is very important and the companies as well as the government should keep working to protect the environment.

\section{References}

[1] R. K. Mudgal, et al., 'Greening the supply chain practices: an Indian perspective of enablers' relationships", Int. J. Adv. Oper. Manag, vol. 1, no. 2, (2009), pp. 151-176.

[2] A. Jindal and K. S. Sangwan, "Development of an interpretive structural model of drivers for reverse logistics implementation in Indian industry", Int. J. Bus. Perform. Supply Chain Model, vol. 5, no. 4, (2013), pp. 325-342.

[3] K. Muduli, et al., "Barriers to green supply chain management in Indian mining industries: a graph theoretic approach", J. Clean. Prod., vol. 47, (2013), pp. 335-344.

[4] K. Mathiyazhagan, et al., "Pressure analysis for green supply chain management implementation in Indian industries using analytic hierarchy process", Int. J. Prod. Res., vol. 52, no. 1, (2014), pp. 188-202.

[5] K. Govindan, et al., "Barriers analysis for green supply chain management implementation in Indian industries using analytic hierarchy process", Int. J. Prod. Econ., vol. 147, (2014), pp. 555-568.

[6] J. Sarkis, "Greening the Supply Chain”, Springer Verlag, (2006). 
[7] P. Rao and D. Holt, "Do green supply chains lead to competitiveness and economic performance?", International Journal of Operations and Production Management, vol. 25, no. 9, (2005), pp. 898-916.

[8] S. Ashley, "Designing for the environment", Mechanical Engineering, vol. 115, no. 3, (1993), pp. 52-55.

[9] R. Bergstrom, "An annotated essay: environmental affairs", Production, vol. 105, no. 4, (1993), pp. 3641.

[10] J. Gillett, “Ensuring suppliers' environmental performance”, Purchasing \& Supply Management, (1993), pp. $28-30$

[11] E. Maxie, "Supplier performance and the environment", In: International Symposium on Electronics and the Environment, IEEE, San Francisco, CA, (1994).

[12] M. Christopher and H. Peck, "Marketing logistics", Oxford, UK: Butterworth-Heinemann, (1997).

[13] R. P. Kampstra, J. Ashayeri and J. L. Gattorna, "Realities of supply chain collaboration", Int J of Logist Manag, vol. 17, no. 3, (2006), pp. 312-330.

[14] J. B. Sheu, Y. H. Chou and C. C. Hu, "An integrated logistics operational model for green-supply chain management”, Transp. Res. E. Logist Transp. Rev., vol. 41, no. 4, (2005), pp. 287-313.

[15] S. Vachon and R. D. Klassen, "Extending green practices across the supply chain: the impact of upstream and downstream integration", Int. J. Oper. Prod. Manag., vol. 26, no. 7, (2006), pp. 795821.

[16] S. V. Walton, R. B. Handfield and S. A. Melnyk, "The green supply chain: integrating suppliers into environmental management processes”, J. Supply Chain Manag., vol. 34, no. 2, (1998), pp. 2-11.

[17] H. J. Wu and S. C. Dunn, "Environmentally responsible logistics systems, Int. J. Phys. Distrib., vol. 25, no. 2 , (1995), pp. 20-38.

[18] S. Srivastava, "Green supply-chain management: a state-of-the-art literature review", Int. J. Manage, vol. 9, no. 1, (2007), pp. 53-80.

[19] F. Bowen, et al., "The role of supply management capabilities in green supply", Production and Operations Management, vol. 10, no. 2, (2001), pp. 174-189.

[20] S. Kumar and P. Malegeant, "Strategic alliance in a closed-loop supply chain, a case of manufacturer and eco-non-profit organization", Tech. novation, vol. 26, no. 10, (2006), pp. 1127-35.

[21] P. Rao and D. Holt, "Do green supply chains lead to competitiveness and economic performance?", Int. J. Oper. Prod. Manag., vol. 25, no. 9, (2005), pp. 898-916.

[22] J. N. Pretty, et al., "An assessment of the total external costs of UK agriculture", Agricultural Systems, vol. 65, (2000), pp. 113-36.

[23] J. Sarkis, "A strategic decision framework for green supply chain management", Journal of Cleaner Production, vol. 11, (2003), pp. 397-409.

[24] T. Abdallah, A. Farhat, A. Diabat and S. Kennedy, "Green supply chains with carbon trading and environmental sourcing: Formulation and life cycle assessment", Applied Mathematical Modelling, vol. 36, (2012), pp. 4271-4285.

[25] H. Larsena, C. Solli and J. Pettersen, "Supply chain management how can we reduce our energy/climate footprint?", Energy Procedia, vol. 20, (2012), pp. 354-363.

[26] E. Andic, et al., "Green supply chains: efforts and potential applications for the Turkish market", Resources, consservation and recycling, vol. 58, (2012), pp. 50-68.

[27] R. Rostamzadeh, et al., "Application of fuzzy VIKOR for evaluation of green supply chain management practices", Ecological indicators, vol. 49, (2015), pp. 188-203.

[28] J. L. Deng, "Grey Controlling System”, Central Institute of Technology, vol. 10, (1982), pp. 9-18.

[29] T. Yang and C. C. Hung, "Multiple-attribute decision-making methods for plant layout design problem", Robotics and Computer-integrated manufacturing, vol. 23, (2005), pp. 126-137. 
International Journal of $u-$ and e- Service, Science and Technology Vol.8, No. 10 (2015) 